\title{
อ̊FORSETI
}

\section{El deber de información y el estándar de razonabilidad en las garantías implícitas del consumidor*}

\author{
Daniela Supo Calderón** \\ Víctor Hugo Bazán Vásquez ${ }^{* * *}$
}

Resumen. - ¿Es necesario implementar un estándar de razonabilidad dentro de las relaciones de consumo? Partiendo de una respuesta afirmativa a esta pregunta, los autores sustentan su postura desde una perspectiva integral que contemple la noción del deber de información y su relación con la realidad. Ello resulta más relevante en el ámbito de las garantías implícitas donde la normativa del legislador y las condiciones del proveedor no han sido suficientes para regular una determinada situación. Suele omitirse que las expectativas del consumidor son generadas, en su mayor parte, por la información que recibió o debió recibir el consumidor durante el desarrollo de una transacción económica con el proveedor. Por tanto, el presente trabajo recoge las reales implicancias y características del deber de información para así brindar un acercamiento de lo que representa nuestra propuesta: Fomentar el enfoque de abordar el deber de información de forma particular -en cada caso concreto-, desde el plano de las garantías implícitas, con la finalidad de poder obtener decisiones objetivas y congruentes con la realidad.

\begin{abstract}
Is it necessary to implement a standard of reasonableness within consumer relationships? Starting from an affirmative answer, the authors support their position from an integral perspective that contemplates the notion of the duty of information and its relationship and connection with reality. This idea is more relevant in the field of implicit guarantees where the legislation and the conditions set forth by the supplier have not been sufficient to regulate a certain situation. Therefore, the present paper gathers the real implications and characteristics of the duty of information in order to provide an approach of our proposal: Approaching the duty of information in a singular way -in each specific case-, from the level of implicit guarantees, in order to be able to obtain objective decisions that are consistent with reality.
\end{abstract}

Palabras claves. - Protección al Consumidor - Deber de información - Estándar de Razonabilidad - Idoneidad - Garantías Implícitas - Transacción Económica - Parámetros objetivos.

Keywords. - Consumer Protection - Information Duty - Reasonableness standard suitability - Implied warranties - Economic Transaction - Objective parameters.

* Las opiniones expresadas en el presente artículo son responsabilidad exclusiva de los autores y no necesariamente reflejan la posición de los entes de los que forman parte y/o representan.

** Abogada por la Universidad de Lima. Actualmente se desempeña como Abogada Asociada del área de Propiedad Intelectual en Rodrigo, Elías \& Medrano Abogados.

*** Abogado por la Pontificia Universidad Católica del Perú. Actualmente se desempeña como Asistente Legal en la Sala Especializada en Protección al Consumidor del Tribunal del INDECOPI. 


\section{Introducción}

Un componente esencial y a la vez controversial en materia de protección al consumidor, recae en el rol de la información dentro de la dinámica entre proveedores y consumidores. Su carácter esencial se genera como consecuencia del indiscutible papel que juega dicho concepto en esta materia - principalmente a propósito de la denominada asimetría informativa, concepto vinculado con aquella situación de regular disparidad de conocimientos entre consumidores y proveedores. Por otro lado, su carácter controversial se centra, principalmente, en la crítica hacia su regulación y en la reiterada discusión académica sobre la necesidad de establecer parámetros generales de razonabilidad en relación al comportamiento del consumidor.

Al respecto, el presente artículo académico abordará el componente controversial del deber de información, teniendo como finalidad exponer una perspectiva actual y cercana sobre el mismo, a la luz de la normativa y decisiones de los Órganos de Protección al Consumidor del INDECOPI. Así, se resaltará el papel preponderante del deber de información en el Derecho del Consumidor, pero también se propondrán criterios que modulen su interpretación de acuerdo a un contexto determinado.

Específicamente, el presente trabajo recoge las reales implicancias y características del deber de información para así brindar un acercamiento de lo que representa nuestra propuesta: Fomentar el enfoque de abordar el deber de información de forma particular -en cada caso concreto-, desde el plano de las garantías implícitas, con la finalidad de poder obtener decisiones objetivas y congruentes con la realidad. En otras palabras, buscamos resaltar la importancia de determinar un estándar de razonabilidad para el caso de garantías implícitas, el cual debe ser fijado a partir de la valoración de factores contextuales, tales como, el mercado en el que se desarrolla la transacción, el grado de especialidad del consumidor, la naturaleza del producto o servicio, entre otros.

\section{Nociones generales sobre el deber de información}

La protección al consumidor se constituye como un mecanismo que forma parte del sistema económico previsto en la Constitución Política del Perú y que guarda una perfecta armonización con el esquema de una economía social de mercado en el que vivimos.

Al respecto, corresponde traer a colación lo establecido en el artículo 65 del capítulo dedicado al régimen económico del país, de la Constitución Política del Perú, el cual dispone lo siguiente:

“El Estado defiende el interés de los consumidores y usuarios. Para tal efecto garantiza el derecho a la información sobre los bienes y servicios que se encuentran a su disposición en el mercado. Asimismo, vela, en particular, por la salud y la seguridad de la población".

Tal como se puede apreciar del artículo anteriormente citado, el Derecho del 
Consumidor evoca un régimen de tutela jurídica especial constituido por la garantía del derecho a la información, seguridad y salud de la persona en sus relaciones de consumo o exposiciones a las mismas.

En esta línea, debemos señalar que son varias las ocasiones en las que el máximo intérprete de la Constitución, el Tribunal Constitucional, se ha referido a los derechos que le asisten a los consumidores ${ }^{1}$. Al respecto, ha señalado que resulta claro que la Constitución impone dos obligaciones: (i) garantizar el derecho a la información sobre los bienes y servicios que están a su disposición en el mercado; y, (ii) velar por la salud y la seguridad de las personas en su condición de consumidores o usuarios. Sin embargo, también ha precisado que los referidos derechos no son los únicos que traducen la real dimensión de la defensa consagrada en la Constitución hacia los consumidores, sino que albergan de forma implícita e innominada una pluralidad de derechos genéricos en su naturaleza y que admiten manifestaciones diversas 2 .

$\mathrm{Al}$ respecto, tal como se desprende de la sección introductoria del presente trabajo, éste tiene como finalidad abordar conceptualmente el deber de información desde una perspectiva actual y a la luz de las recientes decisiones emitidas por los Órganos Resolutivos de Protección al Consumidor del INDECOPI, para así brindar un acercamiento de lo que centralmente es parte de nuestra propuesta.

Ahora bien, habiendo abordado la justificación constitucional de la información en el marco de la protección al consumidor, corresponde referirnos puntalmente al mismo.

De acuerdo a la Real Academia Española, una de las acepciones del concepto de la palabra información consiste en definirlo como aquella comunicación o adquisición de conocimiento que permite ampliar o precisar lo que se posee sobre una materia determinada ${ }^{3}$. Justamente será el conocimiento sobre una circunstancia o un bien el que repercutirá en la situación o experiencia de una persona, ya que ello influirá directamente en su conducta, ya sea esto visto desde

1 Ver Sentencias: Sentencia del Tribunal Constitucional Exp. 008-2003-AI/TC, Sentencia del Tribunal Constitucional Exp. No 00013-2012-PI/TC y STC Exp. No 00011-2013-PI/TC.

2 Definitivamente resulta materia de otro artículo abordar lo relacionado a la naturaleza constitucional de los derechos de los consumidores que tutela el INDECOPI. Ello, mucho más aún, teniendo en consideración que el 12 de marzo de 2020, se publicó en el Diario Oficial El Peruano la Resolución No. 038-2020-INDECOPI/COD que dispuso la publicación del Documento de Trabajo Institucional No. 003-2020 denominado "Propuestas relativas al fortalecimiento institucional del INDECOPI", con la finalidad de recibir opiniones y/o sugerencias de la ciudadanía. Las propuestas contenidas en el Documento de Trabajo buscarían fortalecer institucionalmente al INDECOPI a través de una reforma constitucional que incorporaría un nuevo artículo en la Constitución Política del Perú (art. 65-A), a efectos de concederle mayor autonomía y poder reducir el riesgo de interferencias en el desarrollo de sus funciones.

En líneas generales se propone lo siguiente: (i) Que el INDECOPI pase a tener calidad de "Organismo Constitucionalmente Autónomo", (ii) que las funciones del INDECOPI se detallen a nivel constitucional (funciones actualmente asignadas al INDECOPI de conformidad con el Decreto Legislativo No. 1033); y, (iii) que el presidente del Consejo Directivo del INDECOPI sea designado por concurso público y ratificado por el Congreso de la República.

3 Real Academia Española. Consulta realizada el día 27 de julio de 2020. Disponible en: https:// dle.rae.es/informaci\%C3\%B3n 
una perspectiva fáctica o jurídica.

$\mathrm{Al}$ respecto, el derecho de los consumidores al acceso a la información y el deber de los proveedores de brindarla, se encuentra reconocido en los artículos 1.1 literal b) y 2 de la Ley 29571, Código de Protección y Defensa del Consumidor (en adelante, el Código), en los siguientes términos:

“Artículo 1.- Derechos de los consumidores.-

1.1. En los términos establecidos por el presente Código, los consumidores tienen los siguientes derechos:

b) Derecho a acceder a información oportuna, suficiente, veraz y fácilmente accesible, relevante para tomar una decisión o realizar una elección de consumo que se ajuste a sus intereses, así como para efectuar un uso o consumo adecuado de los productos o servicios".

“Artículo 2.- Información relevante.-

2.1. El proveedor tiene la obligación de ofrecer al consumidor toda la información relevante para tomar una decisión o realizar una elección adecuada de consumo, así como para efectuar un uso o consumo adecuado de los productos o servicios.

2.2. La información debe ser veraz, suficiente, de fácil comprensión, apropiada, oportuna y fácilmente accesible, debiendo ser brindada en idioma castellano.

2.3. Sin perjuicio de las exigencias concretas de las normas sectoriales correspondientes, para analizar la información relevante se tiene en consideración a toda aquella sin la cual no se hubiera adoptado la decisión de consumo o se hubiera efectuado en términos substancialmente distintos. Para ello se debe examinar si la información omitida desnaturaliza las condiciones en que se realizó la oferta al consumidor.

2.4. Al evaluarse la información, deben considerarse los problemas de confusión que generarían al consumidor el suministro de información excesiva o sumamente compleja, atendiendo a la naturaleza del producto adquirido o al servicio contratado".

En pocas palabras, se involucra el deber de los proveedores de proporcionar toda la información relevante sobre las características de los productos y servicios que oferten, a efectos de que los consumidores puedan realizar una adecuada elección o decisión de consumo, así como para efectuar un uso o consumo correcto de los bienes y servicios que hayan adquirido.

Así, también teóricamente se indica que la información debe ser veraz, útil, accesible y oportuna al consumidor:

“(...) se estima que la veracidad (o el carácter real) de la información es insuficiente, si esta no posee un atributo de utilidad para el consumidor. (...) se exige que esta información sea comprensible, es decir, con un contenido intelectualmente accesible a un consumidor medio, sin que deba realizar un 
esfuerzo intelectual extraordinario o requiera la asistencia de terceros o procurarse otra información adicional. $(. . .)^{4 \prime \prime}$.

De acuerdo a la interpretación de los artículos anteriormente referidos, debe quedar claro que el deber de información de los proveedores es, a su vez, el derecho a la información de los consumidores. Los proveedores tienen la obligación de brindar a los consumidores la información adecuada o necesaria a efectos de que éstos adopten una decisión de consumo adecuada con sus intereses.

Al respecto, compartimos la posición de la Sala Especializada en Protección del INDECOPI (en adelante, la Sala) al señalar que el deber de información de los proveedores o el derecho a la información de los consumidores, constituye uno de los pilares fundamentales en torno al cual se sostiene la legislación de Protección al Consumidor. Al respecto, la Sala señala lo siguiente:

“(...) en Derecho del Consumidor -cuyo bien jurídico tutelado está constituido por el interés de los consumidores, esto es, que las transacciones económicas que realicen cubran sus expectativas- la información viene a convertirse como un pilar fundamental de esta rama jurídica -que incluso goza de un reconocimiento constitucional- al ser aquel elemento que brinda a los consumidores las herramientas necesarias para adoptar sus decisiones durante el momento de negociación de un servicio y/o producto".

\section{La vinculación entre la información y la idoneidad del producto y/o servicio}

Se suele decir que la información e idoneidad son dos caras de la misma moneda, pues, el traslado de datos hacia el consumidor dota a este último de los insumos necesarios para generar una expectativa sobre la cualidad y características del producto y/o servicio ofrecido.

En efecto, el artículo 18 del Código define a la idoneidad de los productos y servicios como la correspondencia entre lo que un consumidor espera y lo que efectivamente recibe, en función a lo que se le hubiera ofrecido, la publicidad e información transmitida, entre otros factores, atendiendo a las circunstancias del caso $^{5}$.

$\mathrm{Al}$ respecto, la asimetría informativa no es un fenómeno que se intente o pretenda corregir, ya que su sola configuración hace posible que los bienes ofrecidos en el mercado tengan un valor y así existan suficientes incentivos para ser creados y

4 SANZ SALGUERO, Francisco Javier. “Estado de la cuestión del deber de información de los proveedores desde una perspectiva normativa, en materia de protección al consumidor". En Revista de Derecho Universidad San Sebastián. 2018. p. 34.

5 Artículo 18.- Idoneidad. Se entiende por idoneidad la correspondencia entre lo que un consumidor espera y lo que efectivamente recibe, en función a lo que se le hubiera ofrecido, la publicidad e información transmitida, las condiciones y circunstancias de la transacción, las características y naturaleza del producto o servicio, el precio, entre otros factores, atendiendo a las circunstancias del caso. La idoneidad es evaluada en función a la propia naturaleza del producto o servicio y a su aptitud para satisfacer la finalidad para la cual ha sido puesto en el mercado. Las autorizaciones por parte de los organismos del Estado para la fabricación de un producto o la prestación de un servicio, en los casos que sea necesario, no eximen de responsabilidad al proveedor frente al consumidor. 
comercializados. En vinculación a este concepto, el traslado de información relevante tiene como objetivo reducir, temporalmente, una brecha de conocimientos preexistente para hacer posible que el consumidor obtenga cierto tipo de información que le resulte importante para llevar a cabo una transacción.

Ahora bien, esta denominada "información relevante" puede ser previamente determinada en una garantía ${ }^{6}$, ya sea, a criterio de un legislador dentro de una norma (garantía legal), de un proveedor bajo lo expresado en un contrato u otra fuente similar (garantía expresa), o, bajo la propia expectativa que guarde un consumidor en atención a su propia experiencia y el contexto que envuelve una transacción comercial (garantía implícita).

Así, están las garantías legales, las cuales se encuentran establecidas en piezas legislativas. Por ejemplo: En el caso de los productos alimenticios, el artículo 32 del Código, obliga a los fabricantes a consignar en la etiqueta de sus productos una denominación que sea acorde a su naturaleza y composición 7 , y, en el supuesto que no se cumpla con dicha disposición, no solo estaremos ante una transgresión del deber de información - al no trasladar de manera adecuada los datos sobre la naturaleza del bien ofrecido - , sino también al deber de idoneidad, al no poner a disposición del mercado un producto que contenga aquellas características que debe poseer en su etiquetado (garantía legal).

Por otro lado, en el caso de garantías expresas, el consumidor genera su expectativa a partir de la información que pudo haber recibido, ya sea en la

6 El término garantía, en protección al consumidor, se entiende como el conjunto de condiciones, características y propiedades que posee un producto o contempla un servicio.

La distinción y clasificación de este término se encuentra contemplado en el artículo 20 del Código, cuyo contenido es el siguiente:

"Artículo 20.- Garantías

Para determinar la idoneidad de un producto o servicio, debe compararse el mismo con las garantías que el proveedor está brindando y a las que está obligado. Las garantías son las características, condiciones o términos con los que cuenta el producto o servicio.

Las garantías pueden ser legales, explícitas o implícitas:

a) Una garantía es legal cuando por mandato de la ley o de las regulaciones vigentes no se permite la comercialización de un producto o la prestación de un servicio sin cumplir con la referida garantía. No se puede pactar en contrario respecto de una garantía legal y la misma se entiende incluida en los contratos de consumo, así no se señale expresamente. Una garantía legal no puede ser desplazada por una garantía explícita ni por una implícita.

b) Una garantía es explícita cuando se deriva de los términos y condiciones expresamente ofrecidos por el proveedor al consumidor en el contrato, en el etiquetado del producto, en la publicidad, en el comprobante de pago o cualquier otro medio por el que se pruebe específicamente lo ofrecido al consumidor. Una garantía explícita no puede ser desplazada por una garantía implícita.

c) Una garantía es implícita cuando, ante el silencio del proveedor o del contrato, se entiende que el producto o servicio cumplen con los fines y usos previsibles para los que han sido adquiridos por el consumidor considerando, entre otros aspectos, los usos y costumbres del mercado".

7 “Artículo 32.- Etiquetado y denominación de los alimentos .-

El etiquetado de los alimentos se rige de conformidad con la legislación sobre la materia o en su defecto a lo establecido en el Codex Alimentarius.

Los alimentos deben llevar en su etiquetado de manera destacada la denominación que refleje su verdadera naturaleza, sin generar confusión ni engaño al consumidor.

Las alegaciones saludables deben sustentarse de acuerdo con la legislación sobre la materia o en su defecto a lo establecido en el Codex Alimentarius". 
publicidad o en el contrato suscrito con el proveedor. De acuerdo a ello, cada una de las condiciones pactadas o características ofrecidas serán parte de aquello que esperará recibir al momento de la ejecución y/o adquisición de un determinado servicio o producto. Claramente, en este supuesto, en caso exista algún tipo de defecto con el servicio prestado, el consumidor podrá oponer su incumplimiento por cualquiera de las condiciones ofrecidas por el proveedor. Ello, en atención a la información previamente trasladada por este último. En virtud a lo expuesto, cuando el Órgano Resolutivo correspondiente analiza un caso de garantías explícitas, de modo casi automático evalúa el nivel y contenido de la información brindada al consumidor.

Ahora bien, en el caso de las garantías implícitas esta situación se torna un poco más compleja. En efecto, en tanto nos encontramos frente a un escenario en el cual se suscita un supuesto no contemplado en las condiciones pactadas y, por tanto, resulta necesario conocer cuales podrían ser las legítimas expectativas del consumidor respecto del producto o servicio adquirido. Precisamente en este punto es donde se convierte en un elemento trascendental el análisis de la calidad de información. En efecto, ante este supuesto, para estar en la capacidad de determinar qué es lo que hubiera esperado recibir el consumidor, es necesario establecer cuál era el tipo de información que éste hubiera podido poseer.

A continuación, un breve ejemplo que podría resultar ilustrativo para otorgar mayor claridad a esta idea: Un consumidor pone a disposición de un veterinario a su mascota para que le realice una intervención quirúrgica que, en principio, no embarga mayor complejidad. Sin embargo, una vez realizada la referida intervención, la mascota fallece producto de una mala praxis.

En principio, al tratarse de una actividad de medios, no debería presumirse que se garantiza el éxito de la intervención quirúrgica. Sin embargo, bajo una garantía implícita, dada la baja complejidad de la operación, resulta legítimo que el consumidor no espere que la ejecución del servicio pueda conllevar al lamentable fallecimiento de su mascota. De acuerdo a ello, la referida situación podría calificarse como una transgresión al deber de idoneidad que tiene el proveedor.

Es decir, ante un caso como el mencionado, para poder colegir la transgresión al deber de idoneidad, el Órgano Resolutivo debe asumir cuál hubiera sido el tipo de información que tenía el consumidor previo a la ejecución del servicio. Justamente, en el ejemplo referido, la información que poseía el consumidor estaba referida al nivel de dificultad del servicio y el bajo riesgo que conllevaba su ejecución.

De acuerdo a lo expuesto, es claro que resulta materialmente imposible exigir un análisis particular para establecer garantías legales y expresas de información bajo este supuesto8, sino solo para aquellos casos de garantía implícita. En efecto,

8 Evidentemente, no se plantea la posibilidad de exigir un análisis individual del tipo de consumidor para poder elaborar normas y/o políticas contractuales, pues, en este tipo de situaciones será necesario partir de un estándar promedio del consumidor en un mercado relevante. Sin perjuicio de ello, dicha afirmación no nos debe conllevar a pensar que la información en materia de garantías legales y expresas deba estar exenta de un análisis estricto, 
nuestra propuesta únicamente incluye que, en el caso de las garantías implícitas, el análisis de del parámetro de razonabilidad debe ser casuístico e individualizado. Es claro que lo propuesto puede resultar un tanto debatible, pero lo cierto es que este razonamiento ha venido siendo aplicado por el INDECOPI en sus últimos pronunciamientos, conforme se apreciará en la sección final del presente artículo.

En líneas generales, lo expuesto hasta el momento se grafica en el siguiente cuadro:

\section{Gráfico 1}

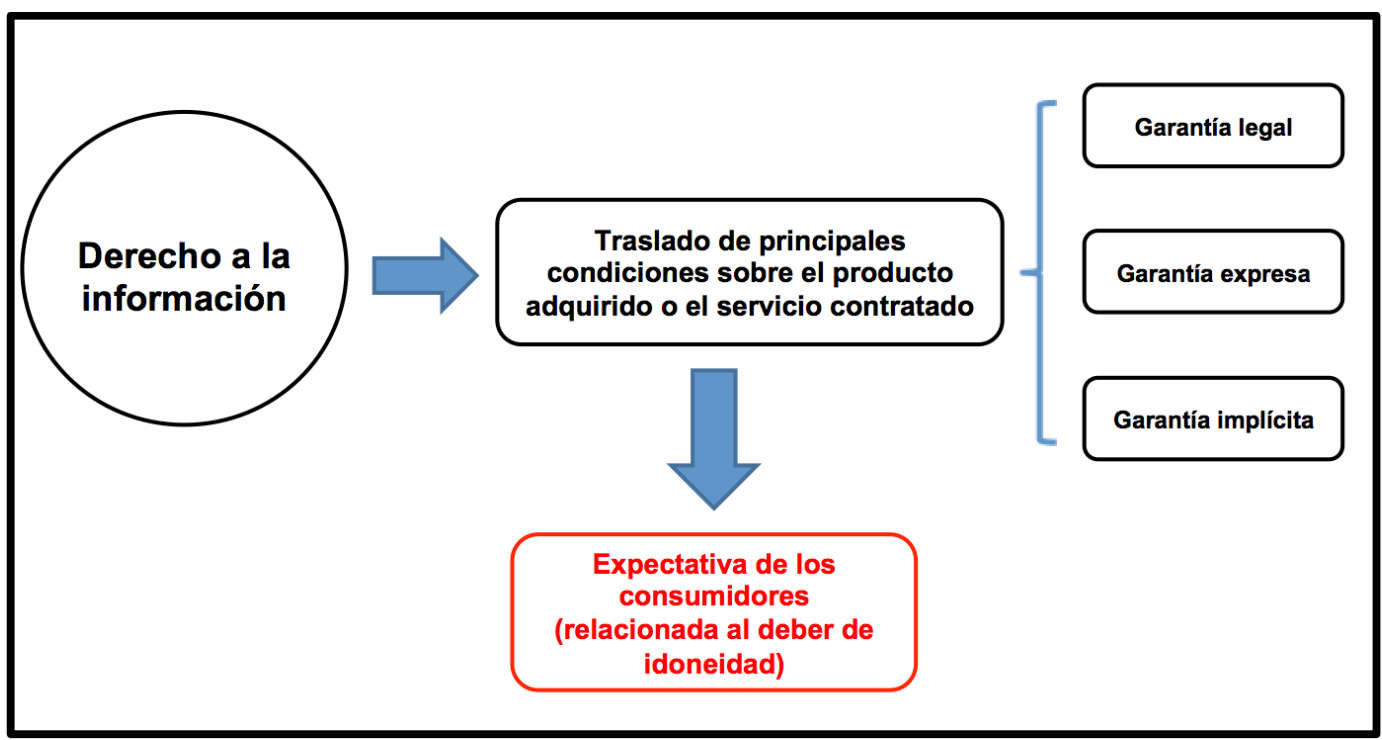

\section{IV. ¿Es necesario contar con un parámetro de conducta en garantías implícitas?}

La intención de incluir un estándar de "consumidor razonable" es usualmente vinculada con el análisis de aquella conducta idónea que debe adoptar el consumidor frente a una oferta. Esta relación no es ajena a la reiterada tentativa de los académicos y legisladores de establecer parámetros o estándares de referencia en relación al comportamiento que debe tener un consumidor en la dinámica de las transacciones comerciales.

En virtud de lo expuesto en el numeral anterior, consideramos que al pensar en establecer un parámetro de debida diligencia en el consumidor, no solo estaremos hablando de un estándar para analizar la idoneidad de un producto o servicio, sino también en la información que debió haber sido trasladada al inicio de una relación de consumo.

Ahora bien, es claro que sí resulta importante establecer parámetros generales de razonabilidad para escenarios donde se elaboran garantías legales y expresas, sin embargo, dentro del marco de garantías implícitas, consideramos preponderante determinar lo que asume un consumidor dentro de un contexto determinado, el cual está regido por distintos factores como la propia naturaleza de la transacción,

sino al contrario, será el legislador o proveedor quienes tendrán, bajo sus propios incentivos y obligaciones, la labor de investigación de mercado para identificar qué conocimientos deben ser trasladados en el marco de una transacción de consumo. 
el lugar donde se realizó, la experiencia, entre otros. En otras palabras, en caso de garantías implícitas, no nos debemos circunscribir únicamente al grado de diligencia o un parámetro de conducta del consumidor, sino que se deben evaluar necesariamente otros factores.

$\mathrm{Al}$ respecto, al momento de detectar la información relevante que tiene o debía tener el consumidor, no se descarta la idea de que la denominada diligencia ordinaria esté presente en la evaluación de casos, pero debemos tomar en cuenta que este concepto no guarda un verdadero contenido sin valorar factores económicos, sociales, geográficos u otros, no solo desde la posición del consumidor -y su experiencia-, sino también desde la propia naturaleza del producto adquirido o servicio contratado.

Hasta el momento, lo expuesto puede leerse como una aseveración un tanto ambigua porque, por una parte, se considera relevante establecer un parámetro de razonabilidad (lo cual puede ser interpretado como un estándar amplio y general) pero, por otro lado, se afirma que para el caso de garantías implícitas, cabe hacer un análisis casuístico de la información e idoneidad.

Lo cierto es que, bajo nuestra postura, podría hablarse de un parámetro general y no por ello, menos técnico- para los supuestos de garantías legales y expresas, en tanto resulta entendible que el legislador o el proveedor puedan estudiar los factores necesarios del mercado y así intentar estandarizar aquella información que debe ser trasladada al consumidor. Sin embargo, un caso distinto ocurre con las garantías implícitas consistentes en aquellas situaciones en las cuales ni la norma ni los acuerdos expresos entre un proveedor y consumidor contemplan una determinada circunstancia suscitada. Es en este tipo de casos en los cuales consideramos que el análisis de un parámetro de razonabilidad debe ser casuístico e individualizado.

De acuerdo a ello, a diferencia de lo que ocurre con las garantías legales y expresas, consideramos que las garantías implícitas deberán atenderse concretamente por el contexto de los hechos. En efecto, en las garantías legales y expresas, este tipo de parámetros son definidos de modo preliminar por el legislador y el proveedor, razón por la que en estas situaciones resulta claro que existirán criterios más amplios (manejando un estándar general ${ }^{9}$ ). Pero, si una situación no ha podido ser definida o calculada por una norma o un contrato, es evidente que el análisis de razonabilidad deberá ajustarse a un estudio del caso concreto.

Tal como lo señala Espinoza, la utilización de parámetros en distintas ramas del Derecho puede ser útil y hasta necesaria ${ }^{10}$, sin embargo, señalamos que pueden existir distinciones al momento de su aplicación. En el caso del Derecho del Consumidor y bajo los propios criterios establecidos en el Código, sostenemos que

9 En el caso de garantías legales se ha previsto una serie de factores objetivos que exijan obligaciones tanto a proveedores y consumidores; y, en el marco de un contrato, el propio consumidor aceptó las condiciones establecidas por el proveedor.

10 ESPINOZA ESPINOZA, Juan. Derecho de los Consumidores. Lima: Editorial Rodhas, 2012, pp. 5051. 
los parámetros de razonabilidad en los casos de garantías implícitas son establecidos por la propia casuística. En relación a ello, si bien somos conscientes de que el tipo de evaluación propuesta puede resultar tediosa, a nuestro criterio, deberá primar la emisión de una decisión ajustada a la realidad y derecho.

Eludir el contexto social y económico para el caso de garantías implícitas nos puede llevar a adoptar, en algunas ocasiones, decisiones radicalmente arbitrarias contra los consumidores, generándose incentivos perversos para que los proveedores puedan omitir el traslado de cierta información relevante al momento de consolidarse una transacción. Como podrá inferirse el denominado estándar de razonabilidad no solo deberá involucrar la perspectiva de la propia experiencia del consumidor, sino también los factores que rodean la relación de consumo, esto es, la interpretación de la información recibida ${ }^{11}$.

En otras palabras, lo que comúnmente se había exigido como el estándar de un "consumidor razonable" para nosotros está orientado a establecer un estándar de razonabilidad que contemple, no solo al consumidor, sino también al entorno que involucra la relación de consumo. Es decir, el lugar y momento de la ocurrencia, así como también la propia naturaleza del servicio y/o producto ofrecido.

\section{La propuesta de un parámetro de razonabilidad en el deber de información}

Distintos autores han señalado la necesidad de que exista la inclusión del estándar de consumidor razonable en el Código, alegando que ello permitirá generar incentivos suficientes para establecer un marco de comportamientos tendientes formar a un modelo de consumidor diligente. Es decir, un agente consciente de las condiciones pactadas y las características mínimas que posee un producto y/o servicio.

Sin embargo, no estamos tan seguros que la referida propuesta sea la solución al problema, pues, aun cuando se incluya este término, serán finalmente los Órganos Resolutivos quienes definirán aquel parámetro de "lo razonable", asumiéndose así el riesgo que su criterio, en ocasiones, pueda ser más cercano a lo que se califica como "ordinario".

11 Bullard manifiesta que es preciso utilizar un parámetro de consumidor razonable que debe estar recogido en la norma, basándose para ello en dos razones: (i) resulta absurdo plantear un estándar en función a lo que las personas son, ya que si los consumidores tienen algún comportamiento irracional, lo ideal consistía en buscar incentivos para que dicha conducta cese; $\mathrm{y}$, (ii) los consumidores no se comportan en el mercado como idiotas, pero igual era necesario establecer un estándar para corregir situaciones aisladas de irracionalidad. BULLARD GONZÁLES, Alfredo. “¿Es el consumidor un idiota? El falso dilema entre el consumidor razonable y el consumidor ordinario". En Revista de la Competencia la Propiedad Intelectual, núm. 10, p. 8.

Al respecto, coincidimos parcialmente con dicho autor, y reiteramos que nuestra postura radica en que el establecimiento de parámetros generales de razonabilidad es necesario para escenarios donde se elaboran garantías legales y expresas; sin embargo, discrepamos que un mismo nivel de análisis sea aplicado para el caso de las garantías implícitas. 
En virtud a ello, nos preguntamos: ¿Nos encontramos ante un grave problema si la norma de protección al consumidor no establece expresamente un estándar de razonabilidad? Consideramos que no.

Con el fin de dotar de contexto la interrogante anteriormente planteada, es necesario remitirnos a los orígenes del referido término en la normativa de protección al consumidor.

La legislación de protección al consumidor empezó a concebirse a partir del Decreto Legislativo 716 y sus modificatorias. Al respecto, el referido Decreto Legislativo no contemplaba dentro de sus disposiciones la noción de "consumidor razonable", "consumidor ordinario" o "consumidor con diligencia ordinaria".

Posteriormente, en el año 2008, el Decreto Legislativo 1045 modificó el artículo 3 del Decreto Legislativo 716, artículo que se encargaba de definir el concepto de consumidor. El texto que se incluyó fue el siguiente:

“a) Consumidores o usuarios.- Las personas naturales que, en la adquisición, uso o disfrute de un bien o contratación de un servicio, actúan en un ámbito ajeno a una actividad empresarial o profesional y, excepcionalmente, a los microempresarios que evidencien una situación de asimetría informativa con el proveedor respecto de aquellos productos o servicios no relacionados con el giro propio del negocio. La presente Ley protege al consumidor que actúa en el mercado con diligencia ordinaria, de acuerdo a las circunstancias" (Énfasis Agregado).

Lo incluido por el Decreto Legislativo 1045 en el artículo citado anteriormente no hace mas que recoger la definición de consumidor razonable. De esta manera, el referido Decreto Legislativo incluía el parámetro de conducta comprendida en la "diligencia ordinaria". Sin embargo, el referido Decreto Legislativo quedó derogado por la Ley 29571, el Código. Y, tal como es de común conocimiento, el Código no contempla ninguna disposición referida al "consumidor razonable", "consumidor ordinario" o "consumidor con diligencia ordinaria".

$\mathrm{Al}$ respecto, cuando ocurrió esta modificación distintos autores manifestaron su temor ante el evidente cambio que había sufrido la normativa en esta materia a partir de la vigencia del Código, pues, éste no consignaba aquella parte que indicaba lo siguiente: "La presente Ley protege al consumidor que actúa en el mercado con diligencia ordinaria, de acuerdo a las circunstancias", que sí se encontraba en su predecesor.

Según parte de la doctrina, dicha modificación -u omisión- tendría un efecto incidental pues habilitaría que los Órganos Resolutivos analicen los casos desde la perspectiva de un "consumidor ordinario". Pero, ¿qué implica ser un consumidor ordinario? La jurisprudencia del INDECOPI no la ha desarrollado con amplitud, pero se desprende que viene a configurarse como un piso menor al de un "consumidor razonable". De hecho, es posible encontrar la definición de este último concepto en un lineamiento anterior. Si bien, éste data del año 2001 y 
claramente ya no se encuentra "vigente", nos remitimos al mismo para lograr entender que se concebiría como "consumidor ordinario":

"El principal criterio de interpretación que utiliza la Comisión es el del 'consumidor razonable'. Se trata del estándar utilizado por la Comisión para la solución de cada caso concreto, analizando qué es lo que esperaría un consumidor razonable en la circunstancia controvertida. Ello, porque toda la normativa de protección al consumidor se encuentra dirigida a proteger a consumidores razonables, es decir, a aquel consumidor que actúa con una diligencia ordinaria previsible en ciertas circunstancias.

Este estándar no es el de un consumidor experto o excesivamente exigente y cuidadoso o de uno racional, calculador y frío capaz de analizar cada detalle de las opciones que se le presentan, sino, de una persona que actúa con la diligencia ordinaria que se puede exigir a cualquier persona que realiza una operación de intercambio en el mercado. El fundamento de este criterio de interpretación radica en formar consumidores cuidadosos y responsables, que se informen y tomen las precauciones adecuadas antes de hacer una decisión de consumo. Lo contrario llevaría a formar consumidores irresponsables y poco diligentes a los que la Ley protegería aun en situaciones producidas por su propia irresponsabilidad. Para que el mercado funcione adecuadamente, es necesario que el consumidor actúe con diligencia ordinaria en sus decisiones de consumo, de acuerdo al principio de buena fe. De la misma manera como el derecho común sólo protege la actuación responsable, el derecho de los consumidores sólo debe proteger a los consumidores que actúen con responsabilidad en sus decisiones de consumo. $(\ldots)^{12^{\prime \prime}}$.

Bajo dicha perspectiva, el denominado "consumidor ordinario" vendría a ser aquel que no actúa con diligencia regular, es decir que no adopta las precauciones adecuadas de manera previa a tomar una decisión de consumo y ello podría deberse a las propias limitaciones que tenga al momento de informarse sobre un producto y/o servicio.

Sobre el particular, tal como se mencionó, el aporte del presente trabajo no consiste en optar por el establecimiento de un parámetro con base en una determinada definición ("consumidor razonable" o "consumidor ordinario"), lo cual puede resultar un tanto confuso en su ejecución. Nuestro objetivo es identificar, dentro de un estándar de razonabilidad para las garantías implícitas, cuáles serían los factores que deberán estudiarse en este tipo de situaciones.

$\mathrm{Al}$ respecto, y tal como lo hemos mencionado, consideramos que los factores que deben ser tomados en cuenta deben estar estrechamente vinculados al contexto que envuelve la relación de consumo, y no solo la perspectiva del propio consumidor. Basándonos en esta afirmación, podrán considerarse los siguientes factores: la experiencia, el tipo de producto y/o servicio, la zona geográfica en la que se realizó la transacción, y alguna otra variable que pueda guardar relevancia con un análisis de razonabilidad respecto de la información que pudo haber

12 Ver a detalle en el documento denominado "Lineamientos sobre Protección al Consumidor" aprobado por Resolución 001-2001-LIN-CPC/INDECOPI. 
recibido un consumidor y que pueda influir en la formación de su propia expectativa ${ }^{13}$.

Como se podrá advertir no se brinda una lista taxativa de factores dado que estamos asumiendo que la evaluación de las garantías implícitas y el estándar de razonabilidad se determina de forma casuística. De otro modo estaríamos limitando las herramientas que pueda emplear el Órgano Resolutivo correspondiente al momento de analizar un caso concreto, siendo que lo que debe definir la selección de un factor está definido por su naturaleza incidental respecto de los elementos fácticos del caso.

$\mathrm{Al}$ respecto, tomando como referencia las distintas normas de protección al consumidor - y sus modificatorias- en el Perú, el criterio fijado en el presente trabajo es más cercano -sin ser por ello similar- a lo establecido por el legislador en el Decreto Legislativo 1045. A través del cual se estableció el estándar del "consumidor con diligencia ordinaria", que vendría a ser un símil del consumidor razonable, pero con la precisión de que su determinación sería casuística y adoptando factores vinculados al contexto que rodea al consumidor. En efecto, consideramos que el estándar no solo debe ser definido por aquellos elementos vinculados al consumidor, sino por el entorno de la transacción consolidada con el proveedor.

En virtud a ello, debemos precisar que a nuestro criterio, apuntar a un estándar de "consumidor razonable" resulta un tanto arriesgado, toda vez que existe suficiente literatura que puede indicar que la elección de los consumidores está en muchas ocasiones desvinculada de esta referida "racionalidad" 14 . Distinto es proponer que la información trasladada y la elección de consumo deba atender a situaciones regulares influenciadas por el contexto y entorno, denominando "estándar de razonabilidad" a lo que, bajo este tipo de circunstancias, podría ocurrir en un caso concreto.

A continuación, un ejemplo para ilustrar lo señalado:

\section{Ejemplo 1}

En el marco de la prestación de un servicio de taxi por aplicación (economía colaborativa), un consumidor opta por solicitar una unidad de taxi para transportarse a su centro de labores. Durante el desarrollo del servicio, el consumidor sufre el robo de sus pertenencias por parte del propio conductor,

13 ¿Cuál podría ser otro factor a tomar en cuenta? Consideramos que así como se valoran aspectos económicos o particulares de los consumidores, también es viable la inclusión de otras disciplinas como, por ejemplo, la psicología o el marketing. A propósito de ello, un interesante aporte teórico fue incluido en el artículo denominado "El alcance del deber de información en materia de protección al consumidor: un replanteamiento desde el derecho y economía conductual y el neuromarketing" elaborado por Carlos Rojas Klauer.

ROJAS KLAUER, Carlos. "El alcance del deber de información en materia de protección al consumidor: un replanteamiento desde el derecho y economía conductual y el neuromarketing". En Themis Revista de Derecho, núm. 62, pp. 65-79.

14 MATHIS, Klaus y TOR, Avishalom. "Justifying competition law in the face of consumer's bounded rationality". Notre Dame Law School Legal Studies Research Paper No 1918. p.3. 2018. 
quien además lo agrede físicamente para reducirlo y poder llevar a cabo esta acción. Ante dicha circunstancia, procedió a presentar su reclamo ante el aplicativo, el cual deslindó todo tipo de responsabilidad sobre lo ocurrido al considerar que su papel únicamente se reducía a actuar como intermediario entre el conductor y pasajero.

Asimismo, en dicho contexto, el usuario tomó conocimiento sobre la identidad del conductor y pudo verificar que éste tenía antecedentes penales por robo agravado. Ante ello, procedió a interponer su denuncia contra el aplicativo ante el INDECOPI por presunta vulneración al deber de seguridad. Ello, al haber sido expuesto a un riesgo injustificado por aceptar que un conductor con antecedentes penales pueda realizar este tipo de servicio de transporte urbano.

¿Cómo debería evaluarse este caso? La Autoridad Administrativa debería valorar que, pese a que el proveedor denunciado no realiza de manera directa el servicio de transporte, lo cierto es que, en su calidad de intermediario, debía haber implementado parámetros para la selección de sus conductores, evitando o disminuyendo el riesgo que se produzcan hechos como el denunciado.

Para poder arribar a esta conclusión el INDECOPI debería evaluar la naturaleza del servicio brindado por el proveedor, el cual, si bien consiste en actuar como una plataforma de intermediación, debe tomarse en cuenta que su participación involucra el ofrecimiento de un conductor. Bajo esta perspectiva, como garantía implícita, un consumidor podría tener como expectativa que este tipo de aplicativos elaboran filtros de selección y reducen la posibilidad de que el transporte a su destino sea inseguro.

Tal como se puede advertir, dicha conclusión recoge elementos como la identificación del tipo de servicio, así como también se puede tomar en cuenta el contexto y razones por la que los usuarios prefieren utilizar economías colaborativas para los servicios de taxi. En este punto, debe destacarse que la seguridad ocupa un lugar trascendente en este tipo de decisiones y, por ende, es parte de una garantía implícita que debe brindarse a los consumidores (pese a que no exista una regulación legal o el propio aplicativo no lo ofrezca de forma expresa).

Por otro lado, este tipo de criterio de razonabilidad también es útil para identificar situaciones de error evidente. En efecto, bajo la utilización complementaria del Principio de Buena $\mathrm{Fe}^{15}$, mediante el análisis de un estándar de razonabilidad el

15 El numeral 5 del artículo V del Código contempla en Principio de Buena Fe de la siguiente manera:

"Artículo V.- Principios

El presente Código se sujeta a los siguientes principios:

5. Principio de Buena Fe.- En la actuación en el mercado y en el ámbito de vigencia del presente Código, los consumidores, los proveedores, las asociaciones de consumidores, y sus representantes, deben guiar su conducta acorde con el principio de la buena fe de confianza y lealtad entre las partes. Al evaluar la conducta del consumidor se analizan las circunstancias relevantes del caso, como la información brindada, las características de la contratación y otros elementos sobre el particular." 
Órgano Resolutivo puede estar en capacidad de detectar si una oferta o condición trasladada por un proveedor está claramente alejada de cualquier parámetro de la realidad. Ante este tipo de situaciones, dicha condición recibida -garantía expresano podrá ser tomada válidamente como tal, quedando como opción su evaluación como garantía implícita con base a los estándares de razonabilidad que amerite el caso concreto.

Ello permite no solo garantizar la prevalencia del Principio de Buena $\mathrm{Fe}$, sino también genera los incentivos necesarios para que no exista posibilidad alguna de un aprovechamiento indebido por parte de los consumidores ante la existencia de eventuales errores evidentes en el mercado. Así, este es un claro supuesto en el cual un análisis de razonabilidad aterrizado a un caso concreto -bajo la utilización de factores contextuales- no busca favorecer al consumidor, sino brindar una decisión en la que prime la objetividad y buena disposición de las partes. A continuación, un ejemplo podría facilitar la comprensión de esta idea:

\section{Ejemplo 2}

Dentro de un establecimiento comercial un consumidor observa que el costo de una lavadora es de S/. 1.00 y procede a acercarse a la caja a efectuar la compra del bien por el referido valor monetario. Ante la sorpresa del vendedor, éste le indica al consumidor que no es posible que dicha transacción se efectúe puesto que el precio consignado es erróneo. Esta respuesta indigna al consumidor e interpone una denuncia alegando una negativa injustificada de venta y una transgresión de su legítima expectativa, exigiendo como medida correctiva la aplicación de la condición expresa ofrecida, esto es, la entrega de una lavadora por el precio de S/.1.00.

¿Cómo debería evaluarse este caso? Consideramos que aun cuando inicialmente se advierte la existencia de una garantía expresa reflejada en el traslado de un precio del producto, resulta necesario efectuar un análisis de razonabilidad sobre su contenido, pues, el precio ofrecido claramente no se ajusta a los parámetros establecidos en la realidad. Al respecto, cabe preguntarse lo siguiente: ¿Válidamente un consumidor puede asumir como garantía expresa un precio con desproporción evidente? Nuestra respuesta es negativa. Claramente, para poder llegar a esta conclusión será necesario fundamentarla sobre la base de un análisis de factores contextuales como el precio promedio del producto en el mercado ${ }^{16}$, la experiencia o antecedentes de compra que pudo haber tenido el consumidor ${ }^{17}$ y la propia calidad del bien adquirido.

Ahora bien, a raíz del ejemplo citado, podría deslizarse el presente cuestionamiento: ¿Una decisión como la descrita implica que la autoridad realiza algún tipo de control de precios? Nuevamente la respuesta es negativa.

16 Para ello se puede verificar el precio de un producto de similares características, propiedades y marca en el mercado.

17 El proveedor tendrá la posibilidad de demostrar si estamos ante un consumidor que realiza transacciones con eventual regularidad. 
Lo que en este caso se propone es efectuar un análisis de razonabilidad sobre la información plasmada dentro de una oferta comercial, sin embargo, no se establece cuál debió ser el precio de un producto, sino únicamente evaluar de modo concreto si se generó una legítima expectativa hacia el consumidor.

Como se puede advertir, lo que en un inicio se configura como una garantía expresa, al no guardar un parámetro de razonabilidad, amerita una evaluación propia de una garantía implícita. En la última sección del presente artículo se utilizarán casos reales para determinar cómo actuó la Sala ante situaciones como la descrita.

Ahora bien, hasta el momento, la propuesta efectuada en el presente trabajo puede ser graficada de la siguiente forma:

Gráfico 2

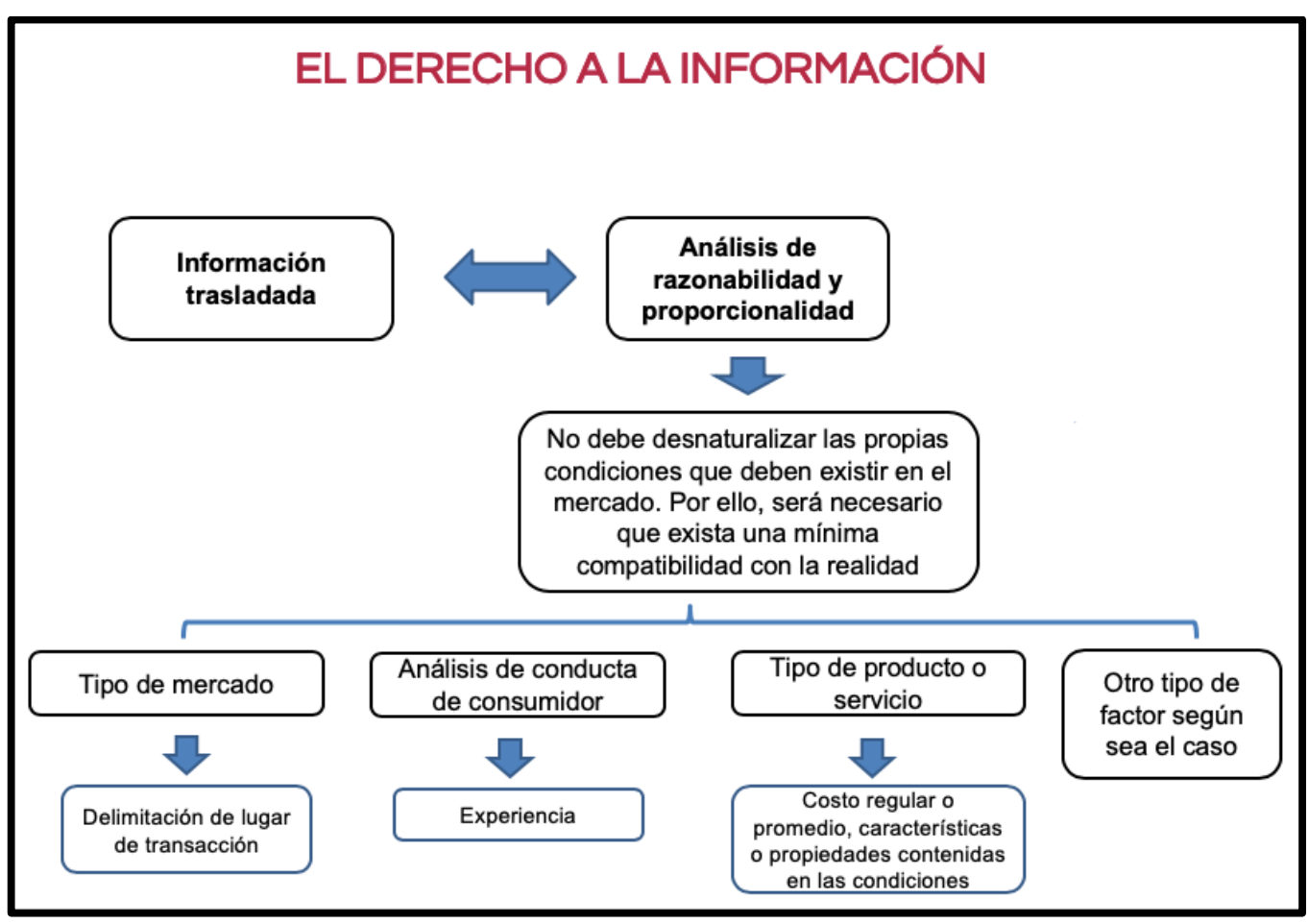

En virtud a lo anteriormente desarrollado, consideramos que no resulta necesaria la inclusión normativa de un parámetro de razonabilidad, en tanto la propia configuración actual del Código habilita a la Administración Pública a utilizarla en plena correspondencia con los principios que rigen la objetividad en el mercado.

Es cierto que una disposición normativa genera mayor seguridad respecto de la aplicación concreta de un razonamiento, no obstante, lo que denotamos es que su inclusión no resulta determinante para que puedan aplicarse razonamientos similares al expuesto en el presente trabajo. Así, en caso se considere pertinente establecer en el Código algún tipo de fórmula legal que contemple un análisis como el propuesto, nuestra sugerencia consistiría en no señalar parámetros que incluyan conceptos que denoten un estudio parcial de los casos, esto es, algún concepto como "consumidor razonable" o "consumidor diligencia ordinaria". En 
tanto ello dejaría entrever que la evaluación de casos únicamente valoraría la realidad del consumidor que, si bien resulta un elemento importante, no refleja un estudio integral de los casos de garantías implícitas.

Finalmente, un último factor al que merece la pena referirnos se origina por la duda en relación a si resulta factible aplicar una propuesta como la descrita para casos que busquen velar por la protección de intereses colectivos y/o difusos. Ello en la medida que si postulamos un análisis casuístico para garantías implícitas, queda el cuestionamiento si ello podría ser factible para aquellos procedimientos en los cuales no se evalúa la situación de un solo consumidor, sino de un grupo determinado o determinable.

Sobre este supuesto, consideramos que la utilización de distintos factores será factible, sin perjuicio de que la evaluación de los mismos resulte más compleja al tener en cuenta que no se identificará la expectativa de un consumidor particular, sino del consumidor peruano en una amplia expresión. Como todo caso de esta naturaleza, se deberá elaborar una ardua labor de investigación de mercado para poder estar en la posibilidad de establecer cuáles son los criterios de información $\mathrm{y}$, por tanto, de idoneidad, de un grupo de consumidores.

En virtud a las consideraciones expuestas, consideramos que actualmente los Órganos Resolutivos correspondientes cuentan con las herramientas jurídicas necesarias para poder aplicar un estándar de razonabilidad en los procedimientos. Sin embargo, es importante precisar que, además, la propuesta señalada involucra un esfuerzo institucional por parte del INDECOPI, consistente en brindar a los Órganos Resolutivos las herramientas técnicas y académicas suficientes para poder efectuar un análisis integral -en ocasiones multidisciplinario- de los casos según amerite las circunstancias. Debe recordarse que, bajo la dinámica cambiante del mercado, son más recurrentes los casos de garantías implícitas $\mathrm{y}$, por ende, surge con mayor urgencia la necesidad de otorgar predictibilidad al mercado respecto del modo de analizar el comportamiento de los consumidores y proveedores.

\section{Análisis de casos prácticos}

Tal como lo señalamos en la sección introductoria del presente artículo, uno de nuestros objetivos es poder verificar la aplicación de los criterios utilizados sobre el estándar de razonabilidad en garantías implícitas por los órganos resolutivos de protección al consumidor, especialmente, la Sala como segunda y última instancia administrativa en materia de protección al consumidor.

Por ello, a raíz de los casos que citaremos se podrá advertir la utilidad del parámetro de razonabilidad en dos (2) tipos de situaciones: (i) casos en los cuales se determina la relevancia de información con base al análisis de distintos factores que contemplen el contexto de la relación de consumo; y, (ii) casos en los cuales se aprecia la existencia de errores evidentes en las condiciones ofrecidas por los proveedores $\mathrm{y}$, en los cuales la aplicación de un parámetro de razonabilidad coadyuvó o hubiera podido facilitar la emisión de un pronunciamiento objetivo. 


\section{i. $\quad$ Caso 1}

En el procedimiento tramitado bajo Expediente 0014-2017/CC2-INDECOPI, se denunció a una empresa automotriz por promocionar un vehículo a US\$149.00 y, posteriormente, negarse a realizar la venta en los referidos términos. En el referido caso, el consumidor denunciante señaló que la empresa denunciada habría difundido 2 anuncios ${ }^{18}$ a través de la radio, los cuales indicarían que es posible llevarse un auto de la marca de la empresa automotriz a US\$149.00. Sin embargo, cuando acudió al establecimiento de la empresa automotriz e indicó que quería dos carros al precio antes referido, el vendedor se negó a vendérselos al referido precio.

Al respecto, a través de la Resolución 3319-2018/SPC-INDECOPI de fecha 28 de noviembre de 2018, la Sala señaló que se debía efectuar un análisis objetivo y contextual del contenido de los dos (2) anuncios radiales y de la información consignada en el sitio web de la empresa denunciada, ello con la finalidad de poder determinar la relación de complementariedad o disimilitud entre ambas fuentes. Sin embargo, precisó que aun cuando la evaluación para casos en materia de protección al consumidor, está centralmente enfocado en aquel aspecto informativo de los productos o servicios, ello no implica desatender el contexto que rodea la actividad económica que enmarca la relación de consumo. Dicho en otros términos, señaló que si bien el hecho controvertido reside en poder efectuar una lectura exacta de las fuentes referidas en la oferta de la empresa denunciada, lo cierto es que la labor interpretativa no sólo abarcará un aspecto literal de su contenido, sino también valorará el tipo de mercado en el que se desarrolla.

Específicamente, señaló:

“(... ) Si bien el hecho controvertido en este extremo reside en poder efectuar una lectura exacta de las fuentes referidas en la oferta de MC Autos, lo cierto es que la labor interpretativa no sólo abarcará un aspecto literal de su contenido, sino también valorará el tipo de mercado que desarrolla el agente económico que tiene la calidad de anunciante. Esta labor tiene como finalidad obtener una perspectiva objetiva y razonable sobre la oferta realizada por el proveedor, pues, conforme lo establece el artículo 2.4 del Código, al evaluarse la información debe tomarse en cuenta la naturaleza del producto adquirido o servicio contratado.

$(\ldots)$

18 Anuncio 1: "Si pensabas que heredar el auto de papá era lo mejor, te equivocaste porque también lo heredas con su colección de cassettes de la ola, cinco stickers de SOAT pegados en la luna, el olor a tabaco y su cojín ortopédico. Claro pues, mejor que tu primer auto sea nuevo. Por eso, ahora Mitsubishi te trae el New Mirage con un precio que te quitará la idea de heredar. Llévatelo desde ciento cuarenta y nueve dólares (US\$. 149,00) o quinientos treinta soles (S/530,00). New Mirage, el otro Mitsubishi. Términos y condiciones en www.mitsubishi-motors.com.pe".

Anuncio 2: "Si pensabas que heredar el auto de hermano mayor era chévere, te equivocaste porque también lo heredas con marcas de pucho en los asientos, restos de comida y la guantera rota. Mejor es que tu primer auto sea nuevo. Por eso, ahora Mitsubishi te trae el New Mirage con un precio que te quitará la idea de heredar. Llévatelo desde ciento cuarenta y nueve dólares (US\$. 149,00) o quinientos treinta soles (S/ 530,00). New Mirage, el otro Mitsubishi. Términos y condiciones en www.mitsubishi-motors.com.pe". 
Por ende para poder identificar la potencial existencia de una contradicción o disimilitud entre las fuentes de información brindadas por MC Autos, deberá evidenciarse ello, tanto desde una interpretación objetiva (literal) del contenido, como desde una interpretación de razonabilidad, esto es, bajo el propio contexto del mercado y lógica del consumidor. En caso no se configuren ambos elementos, no será posible concluir que el mensaje del anunciante pueda ser incongruente, dado que, lo contrario, podría conllevar a emitir una decisión restrictiva, desproporcional o ajena de la realidad.

\section{$(\ldots)$}

Pese a que, de una interpretación literal de los anuncios radiales no puede advertirse la precisión de que el precio consignado esté referido al pago de cuotas mensuales necesarias para la adquisición de un vehículo - lo cual fue reconocido por MC Autos -; ello no puede implicar que resulte razonable, en el caso particular, que un consumidor pueda comprender dicho ofrecimiento como el valor total del bien promocionado. Conviene subrayar que, conforme se expuso en líneas anteriores, los elementos fácticos particulares de cada caso podrán determinar el nivel de razonabilidad que pueda tomarse en cuenta para este tipo de controversias".

\section{Comentario:}

Nos encontramos ante un caso que grafica claramente una situación de error evidente dentro de la cual se advierte que, aun cuando exista una condición expresa otorgada por el proveedor (reflejada en el traslado de un precio), dicha información no puede generar una legítima expectativa en el consumidor, pues su contenido no guarda congruencia alguna con la realidad.

$\mathrm{Al}$ respecto, consideramos que la Sala efectuó un análisis correcto, pues, para arribar a esa conclusión, tomó en cuenta factores tales como: el tipo de mercado, la naturaleza del producto y la zona geográfica donde se realizó la transacción. En efecto, la referida instancia administrativa concluyó que, dentro de la ciudad de Lima, lugar donde se realizaba el mayor número de adquisiciones vehiculares al año, no podía concebirse que un consumidor pueda tener como legítima expectativa que el precio de una unidad vehicular -que además no es un bien de consumo masivo- tenga un precio tan bajo.

Al respecto, podría alegarse que el contexto del traslado de información fue a través de un anuncio publicitario y, por tanto, el consumidor podía comprender que el precio correspondía a una promoción especial. Sin embargo, consideramos importante señalar que todo tipo de publicidad tiene dos (2) componentes: (i) el elemento persuasivo, definido como aquel que tiene como finalidad atraer la atención del consumidor e incentivar la adquisición de un producto y/o servicio, sea mediante una oferta, promoción o la puesta a disposición de imágenes que hagan referencia al bien ofrecido; y, (ii) el elemento informativo, definido como aquel que tiene como finalidad trasladar al consumidor de modo objetivo e imparcial un determinado conocimiento sobre las características y propiedad de un producto o servicio. 
En este caso si bien la información sobre el precio del vehículo fue trasladada a través de un anuncio publicitario, ello no da pie a que el consumidor pueda interpretar que el valor económico haya correspondido a una promoción especial brindada por el proveedor. En tanto, del contenido del referido anuncio se desprende que ello fue trasladado como un elemento informativo, sin advertirse algún tipo de particularidad que pueda dar una interpretación contraria. Al guardar dicha característica, correspondía efectuar un análisis objetivo de la información trasladada tal como acertadamente hizo la Sala en el presente caso.

\section{ii. $\quad$ Caso 2}

En el procedimiento tramitado bajo Expediente 0054-2018/CPC-INDECOPI-JUN, un consumidor denunció a una reconocida empresa de juegos de apuesta por presunta infracción al deber de idoneidad.

Lo ocurrido se remonta a los días 26 y 27 de septiembre de 2017, cuando el consumidor denunciante apostó en el juego denominado "¿Qué país clasifica al Mundial 2018?", eligiendo que las selecciones de Brasil, México, Colombia, Costa Rica, Uruguay y Perú lograrían la clasificación.

Posteriormente, una vez, culminadas las clasificatorias, el consumidor solicitó el pago del premio respectivo, pues había acertado en la totalidad de sus jugadas. Sin embargo, el proveedor le negó tal solicitud alegando que había existido un error en la elaboración del juego, razón por la cual las apuestas efectuadas eran inválidas y correspondía la devolución del monto total apostado. Específicamente, la casa de apuestas le explicó que había existido un error en el juego, razón por la que habían publicado una fe de erratas en la cual especificaron que la verdadera premisa del juego era: “¿Qué país ganará el Mundial 2018?”.

Al respecto, a través de la Resolución 1461-2019/SPC-INDECOPI de fecha 3 de junio de 2019, la Sala decidió declarar infundada la denuncia al considerar que, en atención de la propia experiencia del consumidor y al detectarse la existencia de un error evidente en el juego denominado “¿Qué país clasifica al Mundial 2018?”, no correspondía considerar como válidas las jugadas efectuadas por el denunciante.

A mayor abundamiento, la última instancia en materia de protección al consumidor del INDECOPI valoró lo siguiente: (i) el juego publicado contaba entre sus alternativas errores evidentes, pues, entre una elevada cantidad de alternativas, no existía el componente de incertidumbre presente en todos los juegos de apuestas ${ }^{19}$; y, (ii) el nivel de especialización de este tipo de juegos, más aún tomando en cuenta el número de jugadas y el monto de las apuestas.

Específicamente estableció lo siguiente:

19 A la fecha de publicación de la apuesta habían clasificado varias selecciones de fútbol que se encontraban dentro de las alternativas del juego. 
"Por ende, para poder identificar la potencial existencia de una infracción en el juego de apuesta ofertado por Intralot, deberá efectuarse una interpretación objetiva (literal) del contenido de su apuesta, así como una interpretación de razonabilidad de la misma, esto es, tomando en cuenta el propio contexto del mercado y lógica del consumidor para este tipo de eventos. Hay que mencionar que resulta necesaria la configuración de ambos tipos de interpretación; dado que, una omisión de este tipo de análisis, podría conllevarnos a emitir una decisión restrictiva, desproporcional o ajena de la realidad.

Con la finalidad de poder obtener un acercamiento a este tipo de análisis es pertinente efectuar una observación y comprensión integral del juego materia de cuestionamiento; pues, ello posibilitará identificar aquellos rasgos que permitan brindar a este Colegiado una aproximación del contexto en el cual se desarrollaron los hechos, $y$, así poder tener un nivel de certeza sobre los componentes que envolvieron la relación de consumo entablada por las partes. Así, al hacer referencia a un estudio integral del juego de apuesta, esta Sala resalta la importancia de valorar aquellos aspectos fácticos que inciden o pueden incidir en la percepción de un consumidor, pese a que estos no hayan sido mencionados o precisados por las partes durante la elaboración de argumentos en el presente procedimiento" (Énfasis Agregado).

En virtud a las consideraciones anteriormente citadas, señaló lo siguiente:

"De esta manera, en atención a que el juego materia de evaluación fue elaborado en base a probabilidades, $\mathrm{y}$, el otorgamiento de premios estaba sujeto a las mismas; no resulta razonable que el proveedor haya otorgado un margen de probabilidad de acierto respecto de escenarios que, al momento de su publicación, se habían cumplido. En efecto, tal como se mencionó con anterioridad, dentro del juego con premisa "¿Qué país clasifica al Mundial 2018?", el proveedor otorgó un nivel de probabilidad respecto de selecciones de fútbol ya clasificadas, siendo apreciable la existencia de un error evidente en el contenido del juego, cuestión que, en dicho contexto, no permitía amparar y favorecer la obtención de un beneficio por parte del consumidor.

Por tanto, al no evidenciarse una relación de congruencia entre los elementos objetivos y razonables del juego de apuesta denominado "¿Qué país clasifica al Mundial 2018?", así como verificar que sus jugadas fueron realizadas con posterioridad a la publicación de la fe de erratas, esta Sala considera que no se configuró la vulneración de una legítima expectativa del denunciante, en tanto un consumidor no podría albergar la posibilidad de poder obtener un tipo de beneficio respecto de una oferta cuyos componentes tienen un evidente error; caso contrario, podría estarse amparando circunstancias no deseadas y ajenas a la realidad dentro del marco de una relación de consumo" (Énfasis Agregado).

De acuerdo a las consideraciones anteriormente expuestas, la Sala declaró infundada la denuncia. 


\section{Comentario:}

Tal como se puede apreciar, la Sala tomo en cuenta factores como el tipo de mercado y la propia experiencia y nivel de especialización del consumidor. Claramente el nivel de análisis efectuado utiliza un estándar de razonabilidad, sin embargo, éste no se circunscribe únicamente al consumidor, sino que abarca el tipo de juego así como las propias particularidades del mercado en la cual se realizó la transacción. Ello, se ve reflejado al momento de poner relevancia el alto grado de especialización y la detección de los errores evidentes dentro del referido juego.

$\mathrm{Al}$ respecto, debemos precisar que existe un extracto del pronunciamiento de la Sala que resume claramente uno de los puntos centrales de nuestro trabajo:

"Para efectos de evaluar este caso debe tenerse presente que, aun cuando la evaluación de procedimiento en materia de protección al consumidor está centralmente enfocada en velar por el cumplimiento del deber de idoneidad e información en los productos o servicios que se ofrecen en el mercado; ello no implica el hecho de desatender el contexto que dora la actividad económica que enmarca dicha relación de consumo".

Tal como se precisó en este trabajo académico, lo que se propone es efectuar un análisis ajustado a la realidad de los hechos, razón por la cual es congruente valorar los elementos que componen las circunstancias del caso, más allá de la manifestación inicial de voluntades expresada por el proveedor y consumidor. En este punto prevalece el Principio de Buena Fe, pues, aun cuando en un principio la casa de apuestas aceptó la jugada realizada por el consumidor, lo cierto es que, en aras de aplicar el referido principio debe determinarse si la apuesta era válida en el marco de la normativa de protección al consumidor.

Una vez que se realiza este tipo de análisis, puede arribarse a la conclusión que la jugada efectuada por el consumidor no puede considerarse como válida al tener un contenido evidentemente erróneo, no siendo factible otorgar legitimidad a una transacción como ésta, en tanto ello transgrediría cualquier tipo de concepto primario de una economía social de mercado.

\section{iii. Caso 3}

En el procedimiento tramitado bajo Expediente 189-2009/CPC-INDECOPI, una asociación de consumidores denunció a dos empresas que importaban y comercializaban un producto alimenticio (aceite de soya), respectivamente. A criterio de la parte denunciante, en el etiquetado de este tipo de producto se había omitido consignar que se había utilizado como insumo soya transgénica, configurándose así una transgresión de los artículos 5 literal b y 15 del Decreto Legislativo 716 (derogada norma de protección al consumidor ${ }^{20}$ ).

20 Cabe precisar que estas disposiciones normativas contemplaban obligaciones muy similares a las contenidas en la normativa actual. Dichos artículos establecían lo siguiente:

Artículo 5.- En los términos establecidos por el presente Decreto Legislativo, los consumidores tienen los siguientes derechos:

(...) 
Al respecto, a través de la Resolución 0936-2010/SC2-INDECOPI de fecha 6 de mayo de 2010, la Sala efectuó un análisis dividido en tres partes: (i) el desarrollo del deber de información dentro de una economía social de mercado, (ii) la utilidad y relevancia de rotular productos alimenticios; y, (iii) el deber de información sobre la condición transgénica de productos alimenticios. En este último punto, la Sala estableció que, aun cuando no existiera norma que obligara expresamente a los proveedores a consignar en su etiquetado sobre la condición transgénica de sus insumos, lo cierto era que, bajo la aplicación del Principio Precautorio, y debido a la incertidumbre sobre los efectos que tienen los alimentos transgénicos en la salud de las personas, dicha condición resultaba información relevante y, por tanto, debía trasladarse de manera clara y oportuna a los consumidores ${ }^{21}$.

Específicamente, la Sala realizó la siguiente precisión

“En cualquier caso, negar a los consumidores información sobre la condición transgénica de un alimento o de los insumos empleados en su elaboración implica negarles la posibilidad de asumir los riesgos que ello implica por remotos o inciertos que sean, así como impedirles elegir entre premiar o castigar con sus decisiones de compra un modelo de producción o la aplicación de determinadas tecnologías, es decir diluir su poder de definir condiciones en el mercado, y en general eliminar el presupuesto básico para que sean ellos quienes decidan qué productos desean consumir.

La presente Resolución desarrolla por primera vez la noción de información relevante en el caso de alimentos elaborados con insumos transgénicos, hecho que aunado a la posición que ocupan ambas denunciadas en la cadena de comercialización del aceite "Soya" (desarrollado en el punto 47) configura una causal de justificación que elimina la antijuridicidad de haber comercializado el referido producto sin informar a los consumidores que los insumos empleados en su elaboración eran transgénicos".

b) derecho a recibir de los proveedores toda la información necesaria para tomar una decisión o realizar una elección adecuadamente informada en la adquisición de productos y servicios, así como para efectuar un uso o consumo adecuado de los productos o servicios;

(...)

Artículo 15.- El proveedor está obligado a consignar en forma veraz, suficiente, apropiada muy fácilmente accesible al consumidor o usuario, la información sobre los productos y servicios ofertados. Tratándose de productos destinados a la alimentación y la salud de las personas, esta obligación se extiende a informar sobre sus ingredientes y componentes.

Está prohibida toda información o presentación que induzca al consumidor a error respecto a la naturaleza, origen, modo de fabricación, componentes, usos, volumen, peso, medida, precios, forma de empleo, características, propiedades, idoneidad, cantidad, calidad o cualquier otro dato de los productos o servicios ofrecidos.

21 Es importante señalar que en este caso la Sala no determinó la responsabilidad administrativa de los proveedores denunciados por dos razones: (i) los proveedores tenían calidad de importador y comercializador, sin tener conocimiento preciso sobre la composición de los productos, razón por la que la función de etiquetar el producto recaía, primordialmente, sobre el fabricante del mismo; y, (ii) era la primera vez que el INDECOPI establecía un criterio similar, motivo por el cual consideró, bajo la aplicación del Principio de Confianza Legítima, no sancionar a los administrados. 


\section{Comentario:}

La cuestión resaltante en el presente caso está vinculada al análisis de fondo elaborado por la Sala para llegar a colegir si la condición transgénica de los insumos alimenticios se consideraba información relevante y, por ello, debía ser consignada en el etiquetado de los productos. Ello resulta importante, toda vez que para determinar la relevancia de la información se tomó en cuenta factores de naturaleza esencial como el aspecto sanitario y social. De este modo, pese a no mencionarlo de manera expresa, mediante un parámetro de razonabilidad, la Sala identificó cuál era aquella información que debía ser trasladada a los consumidores en el caso particular ${ }^{22}$.

Conforme lo hemos mencionamos de manera breve, no es sencillo poder identificar el contenido de información relevante para casos que evalúan intereses colectivos y/o difusos de los consumidores. En este procedimiento, la Sala realizó un ensayo de justificar por qué para el consumidor peruano sería importante conocer si un producto alimenticio posee un insumo transgénico, siendo esta una cuestión que - más allá de poder coincidir o no con su decisión final - resulta acertada en su razonamiento dada la trascendencia del bien jurídico que busca tutelarse (salud de los consumidores).

Para ello, valoró la importancia del deber de información y desarrolló que, en aquel periodo, no se tenía certeza sobre las consecuencias de la ingesta de este tipo de productos en la salud humana, siendo por ello relevante que un consumidor tenga previo conocimiento del riesgo en el que podría incurrir por la adquisición e ingesta de un bien como el descrito.

\section{iv. Caso 4}

En el procedimiento tramitado bajo Expediente 809-2014/CC2-INDECOPI, un consumidor denunció a una conocida tienda por departamento, en tanto habría efectuado una compra por su portal web y, posteriormente, los representantes de la tienda se comunicaron a indicarle que las compras no habían sido correctamente realizadas y no procederían. Específicamente, el consumidor denunciante había adquirido tres colchones (valorizados en S/ 1,499.00 cada uno aproximadamente) al precio de $S / 1.00$.

Al respecto, a través de la Resolución 3816-2019/SPC-INDECOPI de fecha 2 de diciembre de 2015, la Sala Especializada en Protección al Consumidor, señaló que en tanto el denunciante puso en conocimiento de la tienda por departamento su aceptación a las ofertas por los colchones y al emitir ésta las respectivas órdenes de compra, la referida tienda por departamento se encontraba en la obligación de

22 Debe tomarse en cuenta que, posteriormente, con la entrada en vigencia del Código se incluyó en su artículo 37 la exigencia legal de informar sobre la utilización de insumos transgénicos en el etiquetado de productos alimenticios. Para mayor información, puede revisarse la Resolución 2051-2019/SPC-INDECOPI del 31 de julio de 2019. 
reconocer la oferta publicitada, dado que de lo contrario se estaría afectando las expectativas del denunciante como consumidor.

Específicamente señaló lo siguiente:

“(...) frente a un contrato de compraventa singular llevado a cabo a través de la web, es decir internet, por lo tanto se necesitaba que la propuesta ofertable del proveedor esté bien diseñada y estructurada en la plataforma virtual del propio proveedor las garantías pertinentes y según fluye de las pruebas presentadas en el presente caso, el señor Chinchay entró a la plataforma virtual de Ripley inició el proceso técnico de compra por internet, seleccionó el producto a adquirir (tres (3) colchones) ingresó su número de tarjeta, se emitió la confirmación por parte del proveedor, quien le otorgó un número de orden por cada compra $(5038262,5035972$ y 5038277) con la frase "Gracias por su compra", es decir, validó y confirmó la transacción otorgando el visto bueno final, emitiéndose las referidas ordenes donde se incluía la fecha correspondiente para que el denunciante se apersone a recoger el producto".

De acuerdo a ello, la Sala señaló que no se puede admitir que se desconozca una operación que ha sido validada y confirmada por el propio proveedor en su propia plataforma web. Además, especificó que en el presente caso no existe ningún elemento probatorio que demuestre que la operación de compraventa por internet haya quedado pendiente de validación o que hubiera existido alguna advertencia u observación en el propio proceso técnico de la plataforma web.

Durante el procedimiento, la tienda por departamento alegó que un consumidor razonable no podría esperar que un colchón de las características ofertadas pueda venderse a un precio tan bajo, siendo que el denunciante pudo haber evidenciado en el mercado que los productos que pretendió adquirir cuentan con un valor aproximado de S/. 1,499.00. Ante ello, la Sala señaló:

“Esta Sala es de la opinión que contrariamente a lo señalado por Ripley, ya se le había generado al señor Chinchay una expectativa válida por los productos ofertados, por lo que el denunciante tenía el derecho a efectuar la compra pues consideró que era una oferta proporcionada por Ripley a través de su página web".

En virtud a lo expuesto, resolvió declarar fundada la denuncia y, como medida correctiva, ordenó que se le entregue al denunciante los tres colchones adquiridos al mismo precio.

\section{Comentario:}

Si bien la decisión adoptada por la Sala en el presente caso resulta totalmente contraria a nuestra propuesta, consideramos pertinente traerla a colación, en tanto, consideramos que es un claro ejemplo sobre un análisis totalmente alejado a la realidad que no considera componentes esenciales para así lograr una decisión coherente.

En efecto, contrariamente a lo señalado en los casos anteriores, en el presente caso la Sala no entra a analizar ningún otro elemento que no sea ceñirse estrictamente 
a la operación de compra venta realizada. Es claro que el presente caso tiene matices particulares, como por ejemplo, un contrato de compra venta debidamente perfeccionado.

Estimamos que es precisamente por ello que la Sala no quiso emitir un pronunciamiento que interfiera directamente con un contrato celebrado entre las partes. Sin embargo, consideramos que la Resolución citada representa un claro ejemplo sobre el análisis que no deben efectuar los Órganos Resolutivos. En efecto, se trata de un análisis que no incluye factores determinantes, como lo son, las características del mercado, el producto ofertado, la experiencia del consumidor, entre otros. Una decisión que haya podido realizar un análisis como el "Caso 2" expuesto, sugeriría que el operador jurídico hubiera podido arribar a una distinta conclusión, haciendo prevalecer el Principio de Buena Fe contemplado en el Código vigente.

\section{Conclusiones}

La información guarda un papel trascendental en la dinámica de una relación de consumo, pues, es a través de este elemento que se generan las distintas garantías que podrá exigir un consumidor en el marco de una transacción económica. De acuerdo a ello, el deber de información viene a ser una obligación inalienable de los consumidores y cuyo contenido deberá guardar plena congruencia con los elementos que envuelven el contexto de la contraprestación.

Al respecto, en virtud a lo señalado en el presente artículo, la identificación del contenido de lo que debe informar un proveedor posee una mayor complejidad en aquellas situaciones en las que prevalece la aplicación de las denominadas garantías implícitas. Ello, toda vez que, en este tipo de casos no se tiene referencia sobre algún ofrecimiento expreso hacia el consumidor, siendo necesario establecer lo que debería primar como expectativa en las condiciones y cualidades de un producto y/o servicio.

En este contexto, consideramos óptimo resaltar la importancia de determinar un estándar de razonabilidad para el caso de garantías implícitas, el cual debe ser fijado a partir de la valoración de factores contextuales que permitan obtener una decisión de carácter objetivo y congruente con la realidad. De acuerdo a ello, a criterio de los autores, lo recomendable es tomar en cuenta una visión integral de los hechos y no solo estudiar el particular entorno que rodea al consumidor, esto es, analizando factores como el tipo de mercado, la característica del bien o servicio, o algún otro tipo de parámetro que coadyuve al operador jurídico a poseer predictibilidad y claridad en la resolución de casos. 